\title{
La pandemia que no vimos venir
}

\section{The pandemic that we didn't see coming}

Gabriel León ${ }^{1}$

Palabras clave: SARS-CoV2; políticas públicas; comunicación científica; gestión de riesgos; pandemia

El año 2007, tres grupos de investigadores -incluyendo a académicos del Departamento de Geofísica de la Universidad de Chile-hicieron un interesante estudio sobre una zona de silencio sísmico que se extendía entre Constitución y Concepción (Ruegg et al., 2009). El estudio -finalmente publicado el junio de 2009- establecía que, en el peor escenario posible, la zona tenía el potencial para generar en el futuro cercano un terremoto de magnitud 8,5 Mw. Ese mismo año, especialistas en enfermedades emergentes publicaron un estudio sobre el potencial de los Coronavirus (CoV) tipo SARS para generar infecciones emergentes y re-emergentes: "La presencia de una gran reserva de virus tipo SARS-CoV en los murciélagos de herradura, junto con la costumbre de comer animales exóticos en el sur de China, es una bomba de tiempo" (Cheng et al., 2007). El 27 de febrero de 2010, un terremoto de magnitud 8,8 Mw con epicentro entre Constitución y Concepción ocurrió de madrugada. Minutos después, un tsunami azotó la costa de Chile. Quinientas veinticinco personas murieron y otras 23 fueron declaradas desaparecidas. ¿Se pudo haber evitado parte de esta tragedia a partir de la evidencia científica? Parece poco probable, ya que pasaron solo ocho meses entre la publicación del estudio que lo advertía y el terremoto. Actualmente, el país cuenta con una red de alerta de tsunamis en toda la zona costera y se modernizaron protocolos y procedimientos vinculados a los planes de emergencia. Sin embargo, pasaron 18 años entre la epidemia de SARS (2002-2003) y la actual pandemia de SARS-CoV2. En ese período, se generó una enorme cantidad de evidencia que alertaba sobre el potencial de la re-emergencia de epidemias tipo SARS, vinculada a la presencia de una gran cantidad de virus tipo CoV y la invasión de nichos ecológicos por parte de nuestra especie. Estos ejemplos generan preguntas muy relevantes en el contexto de otras amenazas que, tarde o temprano, nos golpearán con fuerza, como los efectos que el cambio climático tendrá en el planeta, nuestra especie y forma de vida ¿Cómo se traslada la evidencia científica a la toma de decisiones? ¿Qué rol puede jugar la comunidad científica en alertar sobre riesgos futuros, que siempre parecen menos urgentes que los riesgos presentes? Estas preguntas son urgentes y discutir cómo trasladar la evidencia científica a la toma de decisiones y generar debate público al respecto es un desafío gigantesco. "Basado en evidencia" parece de perogrullo en el ámbito académico, pero en la vida cotidiana resulta a lo menos desconcertante verificar como se toman decisiones. En 1974, los sicólogos cognitivos Amos Tversky y Daniel Kahneman -este último ganador del Premio Nobel de Economía 2002- publicaron un estudio que se ha convertido en uno de los más influyentes en el área de la toma de decisiones en ambientes de incertidumbre (Tversky \& Kahneman, 1974) y que fue fundamental para delinear algunas conclusiones sombrías sobre nuestro proceso de toma de decisiones: cuando enfrentamos situaciones de incertidumbre, no analizamos la información disponible de una manera racional; por el contrario, empleamos atajos mentales que nos lleva a tomar decisiones que pueden tener consecuencias nefastas. Sabiendo todo esto, resulta fundamental que saquemos conclusiones claras con respecto al manejo que la actual crisis sanitaria ha tenido en diferentes partes del mundo. Ya en 2002-2003, para la epidemia de SARS, se criticó a nivel global es secretismo con el que el gobierno chino manejó el asunto, que finalmente salió a la luz gracias a Carlo Urbani, médico italiano que trabajando en Hanoi alertó a las autoridades de la OMS sobre una enfermedad nueva (el Dr. Urbani murió por SARS en marzo del 2003 en Tailandia) (Fleck, 2003). En esta ocasión el manejo de China tampoco fue el óptimo y el médico que denunció esta nueva "neumonía atípica"-el Dr. Li Wenliang, que por cierto también murió víctima de la enfermedad que ayudó a describir- fue perseguido por las autoridades por alterar el orden público (Mahase, 2020). Reconocer las nuevas amenazas y reaccionar a tiempo parecen ser dos lecciones muy relevantes. Países como Corea del Sur hicieron grandes esfuerzos por diagnosticar a la mayor cantidad posible de personas y esa disminución de la incertidumbre diagnóstica parece haber contribuido a hacer que la epidemia progresara de manera

(1) Centro para la Comunicación de la Ciencia, Universidad Andrés Bello. Santiago, Chile. 
más lenta, al tomarse las medidas adecuadas (lacobucci, 2020). La vigilancia epidemiológica también parece clave: países que fallaron en detectar prontamente su primer caso -como ocurrió en Italia o EEUU- han mostrado una progresión más rápida de casos una vez que comenzaron a diagnosticar. La comunicación clara de los riesgos a la población general, así como la transparencia a la hora de entregar los datos, parecen ser también fundamentales para generar el compromiso social que la respuesta a una pandemia requiere. Es importante analizar las diferentes respuestas que esta emergencia sanitaria ha tenido en distintos lugares, dependiendo de los contextos y recursos disponibles. Será un insumo muy valioso para el futuro y permitirá sacar importantes conclusiones. Muy probablemente una de las más relevantes se relacione con cómo los países deben tener sólidos, bien financiados y modernos sistemas de salud pública, que garanticen a los Estados -en la medida de lo posible- la robustez necesaria para responder a un escenario como el actual. Sin embargo, parece muy probable que, pasada la tormenta, archivemos las conclusiones en algún sótano oscuro, las que solo saldrán a la luz cuando nos toque hacerle frente a la siguiente pandemia y nos preguntemos colectivamente ¿cómo fue que no la vimos venir? Espero equivocarme.

\section{Referencias}

Cheng V, Lau S, Woo P \& Yuen K. (2007) Severe Acute Respiratory Syndrome Coronavirus as an Agent of Emerging and Reemerging Infection. Clin. Microbio. Rev. 20, 660-94.

Fleck F. (2003) Obituary: Carlo Urbani. Br. Med. J. 326, 825.

lacobucci G. (2020) Covid-19: What is the UK's testing strategy? Br. Med. J. 368, m1222.

Mahase E. (2020) Coronavirus: doctor who faced backlash from police after warning of outbreak dies. Br. Med. J. 368, m528.

Ruegg, JC, Rudloff A, Vigny C, Madariaga R, de Chabalier JB, Campos J, Kausel E, Barrientos S \& Dimitrov D. (2009) Interseismic strain accumulation measured by GPS in the seismic gap between Constitución and Concepción in Chile. Phys. Earth Planet In. 175, 78-85.

Tversky A \& Kahneman D. (1974) Judgment under Uncertainty: Heuristics and Biases. Science 185, 1124-31.

Mahase E. (2020) Coronavirus: doctor who faced backlash from police after warning of outbreak dies. Br. Med. J. 368, m528 